\title{
Os mosquitos e o Estado no relatório do chefe do Serviço de Saneamento e Profilaxia Rural da Bahia, 1922
}

\author{
Mosquitos and the State in the report by the head of the \\ Rural Sanitation and Prophylaxis Service of Bahia, 1922
}

\author{
Heloísa Helena Rocha \\ Professora, Faculdade de Educação/ \\ Universidade Estadual de \\ Campinas. \\ Campinas - SP - Brasil \\ heloisah@unicamp.br
}

Recebido para publicação em 07.06.2017.

Aprovado para publicação em

25.08.2017.
ROCHA, Heloísa Helena. Os mosquitos e o Estado no relatório do chefe do Serviço de Saneamento e Profilaxia Rural da Bahia, 1922. História, Ciências, Saúde - Manguinhos, Rio de Janeiro, v.25, n.1, jan.-mar. 2018, p.261-279.

\section{Resumo}

Em 1923, o doutor Sebastião Barroso, chefe do Serviço de Saneamento e Profilaxia Rural da Bahia, apresenta um relatório das atividades desenvolvidas no ano anterior. O documento reúne informações sobre as iniciativas coordenadas pela autoridade no tocante às epidemias e à profilaxia rural, acompanhadas de uma compilação dos relatórios dos profissionais responsáveis pelos postos de profilaxia rural e de tabelas contendo dados sobre os trabalhos nas diferentes regiões do estado, as notificações recebidas e as despesas realizadas. O trecho desse documento aqui apresentado permite uma aproximação das discussões em relação ao papel do Estado no enfrentamento dos problemas de saúde pública, num contexto marcado pela recorrente eclosão de surtos epidêmicos, dentre os quais se destacam os surtos de febre amarela.

Palavras-chave: febre amarela; saneamento; profilaxia rural; Sebastião Barroso (1886-1941).

\begin{abstract}
In 1923, Doctor Sebastião Barroso, head of the Rural Sanitation and Prophylaxis Service of Bahia, submitted a report on the previous year's activities. The document contains information on initiatives coordinated by the entity on rural epidemics and prophylaxis, accompanied by a compilation of the reports by the professionals responsible for the rural prophylaxis units and tables containing data on the different regions in the state, notifications received, and expenses. The section of this document presented here enables us to investigate the state's role in addressing public health issues in a context marked by recurring outbreaks of epidemics, especially yellow fever.
\end{abstract}

Keywords: yellow fever; sanitation; rural prophylaxis; Sebastião Barroso (18861941).

http://dx.doi.org/10.1590/S0104-59702018000100015 
A febre amarela volta a ocupar espaço no noticiário cotidiano e a se impor entre as apreensões daqueles que vivem em diferentes regiões do Brasil. A confirmação da contaminação e morte de macacos e o registro de casos confirmados da doença em seres humanos fazem ressurgir velhos temores e ansiedades. ${ }^{1} \mathrm{~A}$ ampliação das áreas de risco e as estatísticas de mortalidade pela febre amarela têm exigido urgentes providências, ganhando espaço na mídia e, ao mesmo tempo, mobilizando estudiosos e autoridades em torno de investigações e medidas que incluem campanhas de vacinação da população. Novamente os mosquitos - que tantas vidas têm roubado e tantos estragos têm produzido, nos surtos recorrentes de dengue e nos episódios recentes de chikungunya e zika vírus - assombram a vida dos brasileiros e daqueles que cruzam as fronteiras deste imenso país, colocando todos em sobressalto e reclamando a ação dos poderes públicos. ${ }^{2}$ Medo, pânico, riscos, ameaça, alerta, emergência são alguns dos termos que permeiam a linguagem que registra o aumento do número de casos confirmados da doença e de mortes.

Os surtos de febre amarela não são um problema novo em nosso país, como evidencia o excerto do documento que aqui se apresenta, escrito há quase um século. Sua leitura pode nos aproximar das questões envolvidas no enfrentamento dessa doença nas décadas iniciais do período republicano - considerada por Hochman (1998, p.156) "o paradigma brasileiro de interdependência sanitária", tendo em vista as discussões que suscitou, bem como as providências e negociações que exigiu. O trecho selecionado oferece alguns indícios das ações de combate às epidemias, capitaneadas pelo chefe do Serviço de Saneamento e Profilaxia Rural da Bahia, doutor Sebastião Mascarenhas Barroso (1886-1941), durante 1922. De modo mais específico, traz elementos para uma leitura das posições dessa autoridade sanitária em relação à responsabilidade do Estado quanto aos problemas de saúde pública. A sua atuação na chefia desse órgão insere-se no âmbito dos convênios que viabilizaram, no período, a ação do governo federal nos estados, com o intento de lidar com os desafios impostos pelos problemas ligados à saúde e ao saneamento. Ação que resultou das amplas discussões em torno dos limites impostos pelo arranjo federativo estabelecido pela constituição republicana, que atribuía aos estados e municípios a responsabilidade pelo enfrentamento dessas questões, deixando a cargo do governo federal a higiene na capital federal, a vigilância dos portos e, em casos excepcionais, a assistência aos estados.

Sebastião Barroso, autor do documento, era médico formado pela Faculdade de Medicina do Rio de Janeiro, com a tese intitulada Mordeduras de cobra e seu tratamento (Barroso, 1889). Ingressou no serviço público como inspetor sanitário, integrando a equipe de Oswaldo Cruz. ${ }^{3}$ Em sua bagagem, trazia alguns anos de exercício profissional como clínico, no interior dos estados do Rio de Janeiro e de São Paulo. Em Manguinhos, no contato diário com Oswaldo Cruz, aperfeiçoou-se na prática da bacteriologia e no conhecimento dos mosquitos. Sua atuação como inspetor sanitário, na época da reurbanização promovida pelo prefeito Pereira Passos na capital da República, foi seguida da inserção nos serviços de profilaxia rural no próprio Rio de Janeiro e, posteriormente, em Minas Gerais, Pernambuco e Bahia, onde chefiou as ações de combate à febre amarela. ${ }^{4}$

O médico foi redator chefe da revista Brasil Médico ${ }^{5}$ e colaborou nos jornais diários $O$ País e Jornal do Commercio. Como parte das iniciativas voltadas para os objetivos de difusão 
dos conhecimentos produzidos no campo da higiene, Barroso integrou a programação de cursos e palestras de divulgação científica da Rádio Sociedade do Rio de Janeiro, fundada em 1923 (Moreira, Massarani, 2001). Além disso, publicou alguns livros, merecendo destaque a "Biblioteca popular de higiene: a saúde para todos", coleção composta de 22 títulos, publicada pela Editora Melhoramentos, na década de 1930, destinada à população em geral e, após o lançamento dos primeiros volumes, também ao público escolar. ${ }^{6}$ Barroso exerceu alguns cargos políticos, como registram as notas publicadas por ocasião do seu falecimento: foi secretário do governo do estado do Paraná, logo após a Proclamação da República; deputado estadual no Rio de Janeiro, por mais de duas décadas; prefeito de Cravinhos, no estado de São Paulo. A ele se referiu o Brasil Médico, no obituário publicado em sua edição de agosto de 1941, nos seguintes termos: "um dos mais acatados higienistas, republicano histórico e deputado estadual, fino escritor, clínico de nomeada"; "eminente legislador, abalizado clínico, intrépido jornalista, dedicado sanitarista, delicado músico e probo administrador" (Necrologia, 16 ago. 1941, p.574-575).

Prefaciando a obra $O$ médico na ciência, na profissão, na sociedade, na qual Barroso compendia algumas das suas experiências como clínico, com destaque para os seus primeiros anos de exercício profissional, Miguel Couto (1934), presidente da Academia Nacional de Medicina, chama a atenção para os predicados do médico, procurando destacar a sua inserção nos mais variados campos. Tal característica, comum a essa geração de médicos, autoriza a pensá-los, conforme assinalam Machado et al. (1978), como "cientistas sociais", em cuja atuação se integravam conhecimentos de estatística, geografia, demografia, topografia, história, com base nos quais buscavam compreender a realidade social e, ao mesmo tempo, elaborar modelos de intervenção de caráter preventivo. Segundo as palavras de Miguel Couto (1934, p.5-6) registradas no prefácio dessa obra,

Em Sebastião Barroso reúnem-se várias capacidades - na medicina, na higiene, no jornalismo, na política - presididas por fúlgida inteligência, notável capacidade de observação e de crítica. Começou pelo laboratório, com um trabalho experimental, sobre mordeduras de cobras, mas, entrando na prática da medicina, revelou logo os predicados que compõem um grande clínico - a sabedoria pelo estudo e a penetração pelo hábito do exame minucioso. Quando Oswaldo Cruz resolveu seletar por concurso os auxiliares de sua grande obra, ele fez-se higienista e logrou um dos primeiros lugares entre dezenas de colegas; deputado e senhor da tribuna ninguém o vencia nos debates sobre... finanças; jornalista ostentou conhecimentos enciclopédicos na improvisação diária acerca dos mais diversos problemas sociais; escritor de linguagem sempre elevada e pura.

A ida de Sebastião Barroso para a Bahia, em 1921, deve ser compreendida no contexto das discussões sobre a legitimidade da atuação da União no combate às epidemias, que redundaram na criação do Serviço de Profilaxia Rural, em 1918. A implantação desse serviço se fez acompanhar, no início de 1920, da criação do Departamento Nacional de Saúde Pública (DNSP). Subordinado ao Ministério da Justiça e Negócios Interiores, o DNSP, cuja criação resultou de um movimento político de caráter nacionalista, incorporava em sua estrutura as ações de profilaxia rural, convertendo o Serviço de Profilaxia Rural em Diretoria de Saneamento e Profilaxia Rural. Como parte desse novo ordenamento, estabeleceram-se 
os convênios entre a União e os estados, que tornavam possível a intervenção federal em casos de calamidade pública, mediante solicitação dos estados interessados.

$\mathrm{O}$ acordo firmado entre o DNSP e o governo do estado da Bahia, orientado segundo os propósitos de interiorização das ações de saneamento e unificação dos serviços de saúde no estado, atribuía ao governo estadual a responsabilidade pelo controle das doenças venéreas e da lepra, ficando a profilaxia de outras enfermidades a cargo do órgão federal, sem qualquer ingerência local, fosse ela municipal ou estadual. O documento estabelecia, ainda, que as partes contratantes se comprometiam a aceitar a colaboração da Fundação Rockefeller na execução dos serviços de profilaxia. Por meio desse acordo, a União se comprometia a empregar um montante de 1.500 contos de réis em serviços de higiene e saneamento rural, durante três anos, cabendo ao governo do estado indenizá-la da metade dessas despesas, em um prazo de dez anos. Conforme destaca Pontes (2007, p.87-88), "a partir de então, o combate à febre amarela já não se encontraria mais sob a responsabilidade do Estado e da sua Saúde Pública estadual. Os trabalhos antiamarílicos passaram a se concentrar nas mãos do DNSP". Esse arranjo se manteve até 1923, quando a Fundação Rockefeller passou a assumir o comando integral das ações de combate à febre amarela no estado (Pontes, 2007; Hochman, 1998). As veementes críticas de Sebastião Barroso aos métodos adotados pela agência norteamericana e a insatisfação advinda da subordinação a que se viu lançado, a partir de então, culminaram na sua ruidosa demissão do cargo (Pontes, 2007; Benchimol, 2001).

Da atuação de Barroso na discussão acerca da responsabilidade do governo federal em relação às questões de saúde pública, dá conta um documento datado de 1919, apontado por Hochman (1998, p.83) como o "mais citado estudo sobre constitucionalidade da expansão dos serviços federais de saúde". Tal documento, segundo destaca esse autor, subsidiou os argumentos de juristas e ministros do Supremo Tribunal Federal na defesa da ampliação do conceito de calamidade pública - por meio da inclusão das epidemias -, bem como na reivindicação da ação do Estado em seu combate:

Quando essa calamidade só e exclusivamente afete ao Estado, o Governo federal não poderá intervir sem solicitação do estadual. Não é esse, como erradamente se tem compreendido, o caso de uma epidemia [de cólera] que, embora na ocasião limitada a um Estado, corra no entanto a possibilidade de difundir-se, invadir outros Estados, tornando-se uma ameaça geral, afetando os interesses da Nação inteira. E se o interesse é geral, se não é privativo do Estado, porque comum a vários outros, a União pode sobre ele providenciar, decretar leis a que governos locais se não poderiam opor (Barroso citado em Hochman, 1998, p.83-84).

Em sua atuação no estado da Bahia, Barroso retoma a discussão dessas questões, como se pode observar no excerto do documento selecionado e transcrito. O trecho corresponde à primeira seção, referente ao "Serviço de Epidemias", da parte geral do Relatório apresentado pelo Dr. Sebastião Barroso, chefe do Serviço de Saneamento e Profilaxia Rural no Estado da Bahia, relativamente aos trabalhos executados durante o ano de 1922. Inscrevendo-se entre as exigências regulamentares de prestação de contas, o documento dirige-se às autoridades superiores, reunindo informações sobre as iniciativas coordenadas pelo médico, no tocante às epidemias e à profilaxia rural, acompanhadas de uma compilação dos relatórios dos profissionais responsáveis pelos postos de profilaxia rural espalhados pelo estado. 
O relatório é parte do Arquivo Belisário Penna da Casa de Oswaldo Cruz/Fiocruz (Rio de Janeiro). Contém 128 páginas, seguidas de anexos em forma de tabelas que quantificam os trabalhos realizados pelo órgão durante 1922, nas diferentes regiões do estado, as notificações recebidas, bem como as despesas efetuadas. A leitura do excerto, que versa sobre o combate à febre amarela e à peste, esta última a cargo do governo estadual, pode trazer elementos para a compreensão do processo de estatização da saúde brasileira, contribuindo, em alguma medida, para a reflexão sobre os desafios hoje postos no que tange ao papel do Estado no financiamento do sistema de saúde, num momento em que os mosquitos, com toda a sua coorte de males, novamente se alastram, espalhando apreensões, temores e riscos à vida da população. Registro oficial das ações de Sebastião Barroso na Bahia como chefe do Serviço de Saneamento e Profilaxia Rural daquele estado, órgão subordinado ao DNSP, ${ }^{7}$ o relatório apresenta o registro do conjunto de iniciativas levadas a cabo no exercício do cargo, acompanhado de reflexões sobre as responsabilidades do poder público nas ações de combate às epidemias, como as que podem ser lidas no trecho transcrito.

O documento é atravessado por veementes críticas em relação à divisão de competências entre a União, os estados e os municípios, em matéria de saúde pública, então justificada com base na afirmação da autonomia dos estados, consagrada pela constituição republicana. Segundo avaliava o médico, essa forma de administração das questões sanitárias acarretava sérios prejuízos aos estados dotados de menos recursos e àqueles que faziam oposição à União, ao mesmo tempo que transformava em letra morta os acordos internacionais firmados pelo Brasil, com vistas ao combate a várias epidemias, uma vez que as múltiplas e complexas providências voltadas para a defesa epidêmica ficavam sujeitas a orientações diversas e, em alguns casos, eram totalmente inviabilizadas em função do mandonismo local. Os parágrafos iniciais, em que Barroso informa que a União havia assumido a responsabilidade apenas pelo combate à febre amarela no estado da Bahia, deixando sob o encargo do governo estadual as providências relativas à peste bubônica, não podem ser mais claros quanto às posições dessa autoridade sanitária:

É para lamentar, em primeiro lugar, não haja, em assuntos sanitários, apesar da criação do Departamento, discriminação clara e insofismável da esfera de competências e de deveres entre os poderes da União, do Estado e do Município.

Em matéria de justiça, de navegação marítima e fluvial, de estradas de ferro, correios e telégrafos, de minas, de impostos e outras, a nossa Constituição delimitou e definiu com precisão e minúcia, a natureza e a extensão de cada unidade de poder. Em assuntos sanitários, porém, a atmosfera positivista que dominou a nossa constituinte, e a preocupação quase vesânica de dotar os Estados com a mais ampla autonomia, levaram os elaboradores do nosso pacto fundamental a nem sequer escrever nele as palavras - higiene e saúde pública - como se a vida material do homem não devesse ser o problema capital dos povos organizados (DNSP, 1923, p.7).

Barroso encontrava os argumentos acionados na defesa da centralização administrativa, na área de saúde pública, na atuação de Oswaldo Cruz no Rio de Janeiro, marco na sua formação como sanitarista. Tais argumentos fundavam-se nas tópicas do movimento sanitarista em curso no país, o qual reivindicava "a modernização e centralização dos serviços sanitários e uma política voltada para as doenças de base urbana, mas também a 
prevenção e o controle das endemias rurais" (Benchimol, 2001, p.115). Assim, diante do contraste entre as medidas adotadas na capital federal, que conhecera de perto e em cuja implementação atuara desde os primeiros momentos, e a situação que encontrava agora em um estado distante das benesses do poder central, o médico observava com indignação:

A República tem compreendido que só a capital federal lhe cabe sanear e expurgar dos males epidêmicos. Só ali a febre amarela enfeia a nossa reputação sanitária, deixando que ela se eternize por todo o norte. Só ali nos causa prejuízo a peste bubônica, só ali há uma defesa real e permanente contra o cólera, só ali se deve preocupar com a tuberculose, a sífilis, o alcoolismo (DNSP, 1923, p.8).

O lugar pouco prestigiado ocupado pela saúde pública na agenda do Estado figura como eixo central das críticas de Barroso, no exercício de um cargo que lhe colocava sobre os ombros a responsabilidade pela direção dos serviços sanitários em um estado que, como destaca Hochman (1998), tradicionalmente mantinha uma postura reticente em relação à presença do governo federal. Tal situação é adjetivada pelo médico como "descalabro sanitário", uma vez que deixava nas mãos das autoridades locais, muitas vezes desprovidas de recursos e sujeitas a toda sorte de injunções políticas, o enfrentamento de problemas de tão graves consequências. Nas análises da autoridade sanitária, ganham ênfase os equívocos e as contradições das posições assumidas pelo Estado brasileiro, dentre os quais destaca a iniquidade de exigir que os governos das unidades federativas arcassem com uma parte dos recursos empregados pela União no combate às epidemias e o erro de condicionar esse apoio à aceitação por parte desses governos. Segundo Barroso, era inconcebível pensar que:

A União que pode, sem simples aviso, entrar por um Estado, por um Município, e abrir por ele uma estrada, estender uma linha telegráfica, ocupá-lo com força militar, estabelecer uma coletoria e cobrar impostos, uma agência de correio e transportar valores, e tanta coisa mais, considera-se desarmada diante da calamidade pública de mortífera epidemia. Ela aceita que o Estado possa impugnar-lhe a ação como atentatória da sua autonomia (DNSP, 1923, p.9-10).

Em algumas de suas ponderações, pode-se ouvir o eco das posições defendidas por ocasião do debate que culminou na criação do DNSP. Uma evidência nesse sentido pode ser observada quando Barroso afirma "não se poder compreender um mal epidêmico como interesse localizado" (DNSP, 1923, p.10) - posição considerada esdrúxula, contra a qual já se haviam manifestado jurisconsultos e constitucionalistas, juízes e tribunais. A bandeira defendida pela autoridade, no exercício de um cargo que o colocava diante de problemas de difícil solução, para a qual escasseavam os recursos, já podia ser vislumbrada na citada publicação de 1919, em que o médico afirmava:

O meu vizinho adoeceu por vontade própria; foi a um laboratório e injetou-se uma cultura viva de bacilos coléricos. Se ele se houvesse simplesmente atirado do telhado à rua ou arrebentado os miolos com uma bala ou ingerido uma [sic] grama de estricnina, isso só afetaria a sua pessoa e eu tinha que limitar-me a lamentar a ocorrência. Com os bacilos do cólera o caso muda de figura - eles se vão difundir aos milhões e milhões pelos objetos que terei que tocar, pelos encanamentos da água que terei que beber, pelos esgotos que vão passar por minha casa. E terei que resignar-me, pois as medidas ao meu 
alcance isolado seriam improfícuas, visto ascenderem a tal importância e complexidade, que só o Estado as poderia executar. Mas o Estado não deve tolher a liberdade do meu vizinho de querer adoecer e morrer, ainda que seja para proteger a minha de aspirar à saúde e à vida. E o mal se há de propagar pela cidade inteira, e as cidades vizinhas e os campos serão contaminados, o país todo sofrerá o flagelo, e milhares e milhares de vidas serão sacrificadas (Barroso citado em Hochman, 1998, p.47).

É nessa mesma direção que se posiciona Barroso, investido da autoridade de chefe do Serviço de Saneamento e Profilaxia Rural da Bahia, no diálogo com seus superiores hierárquicos, conforme se pode ler no trecho do relatório selecionado: "Para anular todos os esforços, perder todos os gastos, basta que, no país, um Estado, um município, um lugarejo deixe de ser expurgado do mal. Extinto ele por toda a parte e cessados os serviços, voltará de novo a se espraiar, a se irradiar, do pequeno foco em que ficou inatacado" (DNSP, 1923, p.16).

No que diz respeito ao combate à febre amarela, questão que hoje novamente nos toca de perto, o médico indagava naquele momento:

Como fazer o combate à febre amarela, que visa o mosquito Stegomya calopus, em localidade contaminada, como defender uma povoação ameaçada, sem penetrar no interior das habitações em busca de qualquer caso febril em seu início e para o exame dos depósitos e coleções d'água, sem exigir dos poderes locais e dos proprietários, obras e melhoramentos nos escoadouros, nos encanamentos, nos depósitos das águas, nas instalações das latrinas e mictórios das habitações, lugares e logradouros públicos? (DNSP, 1923, p.11-12).

$\mathrm{Na}$ implementação de tais medidas, a presença da União mostrava-se fundamental, segundo os argumentos defendidos pelo médico, não cabendo nesse, como em outros casos, a afirmação da propalada autonomia dos poderes locais, desprovidos dos recursos necessários para dar conta das ações de combate necessárias e, além disso, sujeitos ao jogo político local. Os dados sobre a febre amarela na Bahia durante 1922, compilados no relatório, apontam para 314 notificações recebidas, 64 óbitos e 5.857 pessoas sujeitas à vigilância médica. Os informes sobre as verbas repassadas pelo governo federal indicam uma descontinuidade no financiamento do serviço. As análises de Barroso sobre a especificidade do combate à febre amarela na Bahia e sobre os riscos da interrupção da campanha, em outro trecho do documento, soam como um alerta:

Custeio dos serviços. É excessivamente dispendiosa a profilaxia da febre amarela na Bahia, principalmente na capital. O extraordinário número de receptáculos d'água determinado pela grande deficiência do abastecimento; a sua distribuição pelo emaranhado escuro de todos os aposentos tornam as visitas da polícia de focos muito demoradas e demandam grande pessoal e avultado material. A umidade atmosférica e as chuvas frequentes, a antiguidade e a forma das coberturas das casas, tornando inevitável a quebra de muitas telhas e o pagamento de quantiosas indenizações, o estrago rápido dos toldos, o amontoado das edificações na parte central da cidade, são condições que complicam enormemente os expurgos e os fazem caríssimos.

Duração da campanha. Como já mostrei linhas atrás, a suspensão dos serviços em Agosto do ano findo, foi ato que graves prejuízos por certo acarretará. Como já em outros documentos tenho feito ver a essa Diretoria, a capital da Bahia é o ponto por excelência da febre amarela. É a cidade do norte talvez de todo o Brasil, 
que com pontos mais numerosos se comunica diretamente. Direta, frequente e rapidamente. Deve ser o último lugar em que os serviços poderão ser suspensos, depois de varrida a moléstia de todo o território nacional. No ano findo, todos os casos explodidos, procederam de fora ou tiveram filiação direta em outros procedidos de fora. No segundo semestre, os dois únicos óbitos se deram em pessoas em que o mal se manifestou em viagem de Barra do Rio de Contas. Do mesmo modo o caso não seguido de morte. Por mais de uma vez, depois que o governo federal chamou a si esta profilaxia neste Estado, podia ter sido declarada extinta a moléstia nesta capital, se o gérmen lhe não voltasse, por vezes de muito longe, trazido pelo homem, no período de incubação. $\mathrm{O}$ mal se não propagava porque prontas providências $\mathrm{o}$ impediam. E a paralisação brusca e completa de todos os serviços, depois de tanto tempo de verdadeira ausência do mal; devendo ser já muito grande o número de receptíveis; reflorescida que se deve achar a fauna culicidiana pelo abandono dos criadouros: - tudo coloca esta cidade na iminência de grave desastre, de epidemia rapidamente disseminável, incêndio voraz de difícil dominação, no dia em que a fagulha de um caso de novo aqui saltar. Será a inutilização de todos os esforços, de todos os dinheiros gastos até agora (DNSP, 1923, p.44-45).

O aumento dos casos de febre amarela, em nossos dias, acompanhado dos temores em relação aos mosquitos e às doenças que por eles podem ser causadas, bem como das discussões sobre as providências a tomar e os responsáveis por tais providências, não são os únicos pontos que nos aproximam das questões que cercaram a atuação do médico Sebastião Barroso, em suas andanças pelo nordeste brasileiro, há quase um século. É preocupante constatar que, apesar de todas as lutas em prol de um sistema de saúde que atenda de modo satisfatório às necessidades de amplas parcelas da população, cada vez mais desprovidas dos recursos mínimos de sobrevivência, algumas das indagações de Barroso guardam uma inquietante atualidade. A leitura desse documento pode nos ajudar a refletir sobre a situação de saúde no país, numa chave que reatualiza as conexões entre os mosquitos e o papel do Estado, uma vez que nos convoca a pensar sobre os descaminhos que mantêm atual o desafio lançado por essa autoridade sanitária, no início da década de 1920, traduzido como o desafio de que o Estado assumisse "o compromisso de, dentro do quatriênio, expurgar da peste e da febre amarela o território nacional" (DNSP, 1923, p.18-19).

\section{NOTAS}

${ }^{1} \mathrm{O}$ clima de apreensão pode ser observado em algumas das notícias publicadas na Folha de S. Paulo, um dos jornais de maior circulação no país, entre novembro de 2016 e abril de 2017: "Febre amarela põe interior de SP em alerta e antecipa vacinação: após morte de homem e macacos, regiões de Ribeirão e Rio Preto adiantam imunização de bebês" (Febre amarela..., 11 nov. 2016); "Surto de febre amarela leva MG a declarar emergência: em todo o Estado são 38 mortes suspeitas registradas desde a semana passada" (Surto..., 14 jan. 2017); "MG tem medo e filas após casos de febre amarela: em cidade com 4 mortes suspeitas, morador chega à $1 \mathrm{~h}$ a posto de saúde para garantir dose" (MG..., 18 jan. 2017); "Ministério admite, após 8 mortes, surto de febre amarela" (Ministério..., 19 jan. 2017); "Minas chega a 23 mortes por febre amarela confirmadas: Governo federal admitiu que há 'surto' da doença" (Minas..., 20 jan. 2017); “São Paulo tem três mortes por febre amarela confirmadas: um dos casos foi 'importado' de Minas Gerais e os demais ocorreram em áreas rurais; não há motivo para pânico, dizem especialistas" (São Paulo..., 24 jan. 2017); "Febre amarela gera corrida a postos e falta de vacina: São Paulo registrou três mortes e há surto em Minas; não há casos na capital" (Febre amarela..., 25 jan. 2017); "Febre amarela 
bate recorde de confirmações no país: com 88 casos comprovados em 3 Estados, surto chega ao maior nível desde 1980" (Febre amarela..., 27 jan. 2017); "Febre amarela é ameaça em todo o país, diz OMS" (Febre amarela..., 28 jan. 2017); "O avanço da febre" (O avanço..., 31 jan. 2017); "Avanço de 2 doenças sobrecarrega saúde: cidades de Minas Gerais têm dificuldade para conseguir diferenciar pacientes com dengue e com febre amarela" (Avanço..., 18 fev. 2017); "Fixada no litoral, febre amarela volta no tempo e traz novo desafio ao país: surto atual ameaça região de mata atlântica, que não estava incluída em área de vacinação" (Fixada..., 22 fev. 2017); "Quando a febre mata: moradora de Ladainha (MG) afirma que filho rejeitou a vacina contra febre amarela e não levou 'nem uma semana para morrer' após entrar em hospital" (Quando..., 7 mar. 2017); "A febre amarela volta ao Rio" (A febre..., 16 mar. 2017); "SP confirma $8^{\mathrm{a}}$ morte por febre amarela no Estado: dos casos, três foram com transmissão local" (SP confirma..., 18 mar. 2017); "Cresce medo de avanço da febre amarela após casos no Rio" (Cresce..., 21 mar. 2017); "Vacinação contra febre amarela será revista: governos e técnicos discutem ampliar área de recomendação e incluir vacina no calendário nacional para crianças" (Vacinação..., 23 mar. 2017); "Salvador registra 4 mortes de macacos por febre amarela" (Salvador..., 30 mar. 2017); "Saúde quer diluir vacina para ampliar doses: após mortes, aumento da procura pela imunização contra a febre amarela provocou redução dos estoques no país" (Saúde..., 31 mar. 2017); "Entrega de vacina de febre amarela deste ano já supera o total de 2016" (Entrega..., 5 abr. 2017); "Governo decide adotar dose única para vacina contra febre amarela" (Governo..., 6 abr. 2017).

${ }^{2}$ A nota publicada no portal do Ministério da Saúde, no dia 20 de abril de 2017, com o intento de recomendar e orientar a vacinação de mulheres que amamentam, alerta: "neste momento o país vivencia um surto de febre amarela, e o Ministério da Saúde tem empreendido esforços para interromper a circulação do vírus nas áreas onde foram registrados casos da doença. É importante que a população residente ou que vão [sic] se deslocar para as localidades com caso de febre amarela sejam vacinadas [sic] conforme a situação vacinal encontrada" (Brasil, 20 abr. 2017). Segundo dados do Ministério da Saúde, até o final do mês de março, foram confirmados 574 casos da doença, sendo que, dos 1.987 casos suspeitos notificados, 487 permaneciam em investigação e 926 haviam sido descartados. Dos 282 óbitos notificados, 71 estavam sendo investigados e 24 haviam sido descartados (Brasil, 30 mar. 2017). Os dados divulgados em 21 de fevereiro confirmavam 292 casos de febre amarela, indicando que, dos 1.337 casos suspeitos, 919 estavam em investigação e 126 foram descartados. Entre os 212 óbitos notificados, 97 haviam sido confirmados, 112 estavam sendo investigados e três foram descartados. A nota informa, ainda, o envio de doses extras da vacina para os estados com registro de casos suspeitos e para aqueles localizados na divisa com áreas onde se notificaram casos da doença (Brasil, 21 fev. 2017).

${ }^{3}$ Sobre a trajetória de Sebastião Barroso e sua atuação nos órgãos de saúde pública, ver Rocha (2017).

${ }^{4}$ As notas fúnebres publicadas na imprensa quando do falecimento de Sebastião Barroso dão conta da atuação do médico como chefe do Serviço de Malária na Zona da Mata (Minas Gerais), durante a administração de Samuel Libânio. Registram também a sua atuação no combate à febre amarela nos estados da Bahia e de Pernambuco. As pesquisas realizadas, no entanto, não possibilitaram localizar documentos produzidos durante a atuação do médico neste último estado.

${ }^{5}$ Vinculado à Faculdade de Medicina do Rio de Janeiro, Brasil Médico surgiu em janeiro de 1887, tendo como objetivos o registro e o comentário das experiências e pesquisas dos médicos nacionais, bem como a divulgação das experimentações desenvolvidas no Rio de Janeiro, destacadamente na área das doenças tropicais. O periódico mantinha estreitas relações com a Sociedade de Medicina e Cirurgia do Rio de Janeiro, servindo como veículo de publicação de atas e trabalhos dessa entidade, cuja criação, assim como a do periódico, inscreveu-se em um conjunto de iniciativas voltadas para a modernização da medicina brasileira.

${ }^{6}$ Para um estudo detalhado dessa coleção, incluindo a sua configuração como impresso de destinação escolar, como fruto da mediação editorial de Lourenço Filho, ver Rocha (2017).

${ }^{7}$ Como esclarece Hochman (1998, p.175), com base nos acordos firmados com os estados, a par do decreto n.13.538, que ampliou e reestruturou o Serviço de Profilaxia Rural, "o Executivo federal indicaria o diretor de profilaxia rural responsável pela organização do serviço no estado $\left(\operatorname{artigo} 6^{\circ}\right)$. Este deveria ser, necessariamente, funcionário da DGSP ou do Instituto Oswaldo Cruz, portanto vinculado diretamente ao Governo Federal e com uma série de vantagens pecuniárias (artigo 13)". Quanto aos trâmites desses acordos, o autor assinala que "qualquer acordo implicava para a União o controle das atividades a serem realizadas e dos recursos financeiros oriundos da própria unidade contratante. Isso sugere que a legislação promovia uma transferência de recursos financeiros e políticos para os serviços sanitários federais". 


\section{REFERÊNCIAS}

A FEBRE...

A febre amarela volta ao Rio. Folha de S. Paulo. Disponível em: http://acervo.folha.uol.com.br. Acesso em: 29 mar. 2017. 16 mar. 2017.

AVANÇO...

Avanço de 2 doenças sobrecarrega saúde: cidades de Minas Gerais têm dificuldade para conseguir diferenciar pacientes com dengue e com febre amarela. Folha de S. Paulo. Disponível em: http:// acervo.folha.uol.com.br. Acesso em: 29 mar. 2017. 18 fev. 2017.

BARROSO, Sebastião Mascarenhas. Mordeduras de cobra e seu tratamento. Rio de Janeiro: Laemmert. Disponível em: http://bore. usp.br/xmlui/handle/123456789/1206page/130/ mode/1up. Acesso em: 6 jan. 2014. 1889.

BENCHIMOL, Jaime (Coord.).

Febre amarela: a doença e a vacina, uma história inacabada. Rio de Janeiro: Editora Fiocruz. 2001.

BRASIL.

Ministério da Saúde. Portal da Saúde. Febre amarela: prazo para lactantes vacinadas voltarem a amamentar é reduzido. Disponível em: http://portalsaude.saude.gov.br/index. php/o-ministerio/principal/secretarias/sas/ sas-noticias/28204-febre-amarela-prazo-paralactantes-vacinadas-voltarem-a-amamentar-ereduzido. Acesso em: 28 abr. 2017. 20 abr. 2017.

\section{BRASIL.}

Ministério da Saúde. Portal da Saúde. Ministério da Saúde destina R\$ 19 milhões para MG, ES, RJ, BA e SP. Disponível em: http://portalsaude. saude.gov.br/index.php/cidadao/principal/ agencia-saude/27946-ministerio-da-saudedestina-r-19-2-milhoes-para-mg-es-rj-ba-e-sp. Acesso em: 28 abr. 2017. 30 mar. 2017.

BRASIL.

Ministério da Saúde. Portal da Saúde. Ministério da Saúde atualiza casos notificados de febre amarela no país. Disponível em: http:// portalsaude.saude.gov.br/index.php/cidadao/ principal/agencia-saude/27675-ministerio-dasaude-atualiza-casos-notificados-de-febre-amarelano-pais-2. Acesso em: 28 abr. 2017. 21 fev. 2017.

COUTO, Miguel.

Prefácio. In: Barroso, Sebastião Mascarenhas. $O$ médico na ciência, na profissão, na sociedade. Rio de Janeiro: Marisa. p.5-6. 1934.

CRESCE...

Cresce medo de avanço da febre amarela após casos no Rio. Folha de S. Paulo. Disponível em: http://acervo.folha.uol.com.br. Acesso em: 29 mar. 2017. 21 mar. 2017.
DNSP.

Departamento Nacional de Saúde Pública. Diretoria do Saneamento e Profilaxia Rural. Relatório apresentado pelo Dr. Sebastião Barros Chefe do Serviço de Saneamento e Profilaxia Rural no Estado da Bahia relativamente aos trabalhos executados durante o ano de 1922. Bahia: Papelaria Brasileira. 1923.

ENTREGA...

Entrega de vacina de febre amarela deste ano já supera o total de 2016. Folha de S. Paulo. Disponível em: http://acervo.folha.uol.com.br. Acesso em: 7 abr. 2017. 5 abr. 2017.

FEBRE AMARELA...

Febre amarela é ameaça em todo o país, diz OMS. Folha de S. Paulo. Disponível em: http:// acervo.folha.uol.com.br. Acesso em: 29 mar. 2017. 28 jan. 2017.

FEBRE AMARELA...

Febre amarela bate recorde de confirmações no país: com 88 casos comprovados em 3 Estados, surto chega ao maior nível desde 1980. Folha de S. Paulo. Disponível em: http://acervo.folha.uol. com.br. Acesso em: 29 mar. 2017. 27 jan. 2017.

FEBRE AMARELA...

Febre amarela gera corrida a postos e falta de vacina: São Paulo registrou três mortes e há surto em Minas; não há casos na capital. Folha de S. Paulo. Disponível em: http://acervo.folha. uol.com.br. Acesso em: 29 mar. 2017. 25 jan. 2017.

FEBRE AMARELA...

Febre amarela põe interior de SP em alerta e antecipa vacinação: após morte de homem e macacos, regiões de Ribeirão e Rio Preto adiantam imunização de bebês. Folha de S. Paulo. Disponível em: http://acervo.folha.uol.com.br. Acesso em: 29 mar. 2017. 11 nov. 2016.

FIXADA...

Fixada no litoral, febre amarela volta no tempo e traz novo desafio ao país: surto atual ameaça região de mata atlântica, que não estava incluída em área de vacinação. Folha de S. Paulo. Disponível em: http://acervo.folha.uol.com.br. Acesso em: 29 mar. 2017. 22 fev. 2017.

\section{GOVERNO...}

Governo decide adotar dose única para vacina contra febre amarela. Folha de S. Paulo. Disponível em: http://acervo.folha.uol.com.br. Acesso em: 7 abr. 2017. 6 abr. 2017.

HOCHMAN, Gilberto.

A era do saneamento. São Paulo: Hucitec; Anpocs. 1998. 
MACHADO, Roberto et al.

Danação da norma: medicina social e constituição da psiquiatria no Brasil. Rio de Janeiro: Graal. 1978.

MG...

MG tem medo e filas após casos de febre amarela: em cidade com 4 mortes suspeitas, morador chega à $1 \mathrm{~h}$ a posto de saúde para garantir dose. Folha de S. Paulo. Disponível em: http://acervo.folha.uol.com.br. Acesso em: 29 mar. 2017. 18 jan. 2017.

\section{MINAS...}

Minas chega a 23 mortes por febre amarela confirmadas: Governo federal admitiu que há 'surto' da doença. Folha de S. Paulo. Disponível em: http://acervo.folha.uol.com.br. Acesso em: 29 mar. 2017. 20 jan. 2017.

\section{MINISTÉRIO...}

Ministério admite, após 8 mortes, surto de febre amarela. Folha de S. Paulo. Disponível em: http:// acervo.folha.uol.com.br. Acesso em: 29 mar. 2017. 19 jan. 2017.

MOREIRA, Ildeu de Castro; MASSARANI, Luisa. A divulgação científica no Rio de Janeiro: algumas reflexões sobre a década de 1920. História, Ciências, Saúde - Manguinhos, v.7, n.3, p.627-651. 2001.

\section{NECROLOGIA.}

Necrologia: Dr. Sebastião Barroso. Brasil Médico, n.33, p.574-575. 16 ago. 1941.

\section{O AVANÇO...}

O avanço da febre. Folha de S. Paulo. Disponível em: http://acervo.folha.uol.com.br. Acesso em: 29 mar. 2017. 31 jan. 2017.

PONTES, Adriano Arruda.

Caçando mosquitos na Bahia: a Rockefeller e o combate à febre amarela: inserção, ação e reação popular (1918-1940). Dissertação (Mestrado em História) - Faculdade de Filosofia e Ciências Humanas, Universidade Federal da Bahia, Salvador. Disponível em: http://www. ppgh.ufba.br/wp-content/uploads/2013/10/ Ca\%C3\%A7ando-Mosquitos-na-Bahia.pdf. Acesso em: 5 mar. 2014. 2007.

QUANDO...

Quando a febre mata: moradora de Ladainha MG afirma que filho rejeitou a vacina contra febre amarela e não levou 'nem uma semana para morrer' após entrar em hospital. Folha de S. Paulo. Disponível em: http://acervo.folha.uol. com.br. Acesso em: 29 mar. 2017. 7 mar. 2017.

ROCHA, Heloísa H. Pimenta.

Regras de bem viver para todos: a Bibliotheca Popular de Hygiene do Dr. Sebastião Barroso. Campinas: Mercado de Letras; Fapesp. 2017.

SALVADOR...

Salvador registra 4 mortes de macacos por febre amarela. Folha de S. Paulo. Disponível em: http:// acervo.folha.uol.com.br. Acesso em: 7 abr. 2017. 30 mar. 2017.

SÃO PAULO...

São Paulo tem três mortes por febre amarela confirmadas: um dos casos foi 'importado' de Minas Gerais e os demais ocorreram em áreas rurais; não há motivo para pânico, dizem especialistas. Folha de S. Paulo. Disponível em: http://acervo.folha.uol.com.br. Acesso em: 29 mar. 2017. 24 jan. 2017.

\section{SAÚDE...}

Saúde quer diluir vacina para ampliar doses: após mortes, aumento da procura pela imunização contra a febre amarela provocou redução dos estoques no país. Folha de S. Paulo. Disponível em: http://acervo.folha.uol.com.br. Acesso em: 7 abr. 2017. 31 mar. 2017.

\section{SP CONFIRMA...}

SP confirma $8^{\mathrm{a}}$ morte por febre amarela no Estado: dos casos, três foram com transmissão local. Folha de S. Paulo. Disponível em: http:// acervo.folha.uol.com.br. Acesso em: 29 mar. 2017. 18 mar. 2017.

SURTO...

Surto de febre amarela leva MG a declarar emergência: em todo o Estado são 38 mortes suspeitas registradas desde a semana passada. Folha de S. Paulo. Disponível em: http://acervo. folha.uol.com.br. Acesso em: 29 mar. 2017. 14 jan. 2017.

VACINAÇÃO...

Vacinação contra febre amarela será revista: governos e técnicos discutem ampliar área de recomendação e incluir vacina no calendário nacional para crianças. Folha de S. Paulo. Disponível em: http://acervo.folha.uol.com.br. Acesso em: 29 mar. 2017. 23 mar. 2017. 


\title{
Relatório apresentado pelo Dr. Sebastião Barroso, chefe do Serviço de Saneamento e Profilaxia Rural no Estado da Bahia, relativamente aos trabalhos executados durante o ano de 1922 (DNSP, 1923, p.5-19)
}

\author{
Exmo. Sr. Dr. Diretor dos Serviços de Saneamento e Profilaxia Rural.
}

Em obediência à disposição regulamentar, venho dar-vos relação e conta das ocorrências havidas e dos serviços sanitários desempenhados no Estado da Bahia, com respeito aos interesses e gestão do Departamento Nacional de Saúde Pública, através dessa Diretoria, durante o ano de 1922. Para maior clareza e método de exposição, dividirei o assunto segundo a categoria do serviço.

\section{Parte Geral \\ Serviço de Epidemias \\ Combate à febre amarela}

O Departamento Nacional de Saúde Pública chamou a si, neste Estado, apenas o combate à febre amarela. Da peste bubônica continuou a incumbir-se o Governo do Estado.

Permita V. Exa. que a propósito desta divisão de encargos expenda considerações que aliás já tenho feito em outras ocasiões e outros lugares, por julgá-las ainda extremamente oportunas.

É para lamentar, em primeiro lugar, não haja, em assuntos sanitários, apesar da criação do Departamento, discriminação clara e insofismável da esfera de competências e de deveres entre os poderes da União, do Estado e do Município.

Em matéria de justiça, de navegação marítima e fluvial, de estradas de ferro, correios e telégrafos, de minas, de impostos e outras, a nossa Constituição delimitou e definiu com precisão e minúcia, a natureza e a extensão de cada unidade de poder. Em assuntos sanitários porém, a atmosfera positivista que dominou a nossa constituinte, e a preocupação quase vesânica de dotar os Estados com a mais ampla autonomia, levaram os elaboradores do nosso pacto fundamental a nem sequer escrever nele as palavras - higiene e saúde pública - como se a vida material do homem não devesse ser o problema capital dos povos organizados.

E ao serem confeccionadas as leis orgânicas, e remodelados os vários serviços públicos, foi despojada a União de prerrogativas que, em matéria sanitária, a lógica, o bom senso, a conveniência pública, o exemplo de todos os povos cultos, exigem incorporadas ao seu patrimônio legal. O movimento que de longa data se vinha fazendo no Império pela centralização dos serviços de saúde pública, como condição primordial à sua eficiência, foi de chofre anulado no novo regime. Do absurdo desse entendimento, da impraticabilidade dessa orientação, resultou o descalabro sanitário em que se tem debatido a República, a 
sua condição de inferioridade manifesta perante as outras nações, o descrédito em que caíram os seus compromissos internacionais assumidos em solenes tratados e convênios.

Esse absurdo entendimento e essa impraticável orientação se refletiram sempre em artigos de lei, contraditórios uns, platônicos outros, inconvenientes muitos.

A República tem compreendido que só a capital federal lhe cabe sanear e expurgar dos males epidêmicos. Só ali a febre amarela enfeia a nossa reputação sanitária, deixando que ela se eternize por todo o norte. Só ali nos causa prejuízo a peste bubônica, só ali há uma defesa real e permanente contra o cólera, só ali se deve preocupar com a tuberculose, a sífilis, o alcoolismo.

É verdade que a decretação do Departamento veio criar possibilidades daqueles serviços nos Estados. O fez, porém, praticando uma iniquidade e um erro. A iniquidade: - criou e destinou impostos a serem pagos por todos os Estados (e esses impostos renderam cerca de 40.000 contos, dos quais nem 10.000 foram dispendidos); mas os Estados que quiserem gozar dos benefícios da lei, deverão pagar metade das despesas. O erro: - tornou dependente de aceitação por parte dos governos estaduais a realização dos serviços. Com esse duplo inconveniente, os habitantes dos Estados pobres e os daqueles cujos governos estiverem em desacordo político com a União ficam privados da proteção a que têm direito, pelo imposto com que para esse fim especial concorrem.

Examinemos por alto os absurdos e as contradições do modo por que a República tem encarado os negócios sanitários.

Como não podia deixar de ser, só à União foi permitido efetuar tratados e convênios internacionais. E essa União que, sponte sua, sem obrigação constitucional expressa que o determinasse, muito ao contrário, infringindo princípios gerais da Constituição a lhe conferirem ampla esfera de ação em tudo quanto seja 'interesse geral' do país, essa União que de todas as prerrogativas se despojara, assinou tratados e convênios sanitários, comprometendo-se, perante o mundo civilizado, a tomar, em todo o seu território, determinadas e especificadas medidas de combate e de defesa contra a peste, a febre amarela, a cólera e outras que se viessem a incluir, medidas que considera, se não explícita, pelo menos consuetudinariamente, encargo e competência dos Estados. Nesses tratados a União não diz: ... 'se comprometerá a obter que os Estados realizem', mas se empenha categoricamente: ... 'O Brasil realizará'... Essa dubiedade de ânimo com que têm sido assinados os nossos tratados sanitários não deve ter escapado ao olho vigilante do estrangeiro.

A União que pode, sem simples aviso, entrar por um Estado, por um Município, e abrir por ele uma estrada, estender uma linha telegráfica, ocupá-lo com força militar, estabelecer uma coletoria e cobrar impostos, uma agência de correio e transportar valores, e tanta coisa mais, considera-se desarmada diante da calamidade pública de mortífera epidemia. Ela aceita que o Estado possa impugnar-lhe a ação como atentatória da sua autonomia. Por sua vez alguns Estados concebem que sob o mesmo fundamento de autonomia também o Município lhe recuse a interferência. Chamam a isso 'intervir' em assunto de peculiar interesse do Estado ou do Município. E todos cruzam os braços para o gáudio de sectarismo positivista e por fetichismo a uma autonomia levada à culminância de verdadeira soberania; apesar dos artigos constitucionais que só levam à conta de autonomia do Estado ou do Município aquilo que exprimir o seu exclusivo interesse, e afirmam caia na competência da União 
tudo quanto seja de interesse geral do país; apesar de ser meridiana verdade não se poder compreender um mal epidêmico como interesse localizado; apesar de contra tão esdrúxula compreensão se haverem já manifestado todos os jurisconsultos e constitucionalistas, todos os juízes e tribunais do país. E todos cruzam os braços porque o Município não tem recursos, não sabe ou não quer combater o mal; porque à ação do Estado e da União se levanta o duende da autonomia municipal. E o mal se alastra e se estende a outros Municípios, a outros Estados, a todo o país.

Uma simples estrada de rodagem, um fio telefônico ou telegráfico, uma coletoria de sentinela a uma fábrica, um quartel, uma agência de correio etc. são serviços determinados por interesses gerais do país que a União pode realizar quando e onde quiser; uma epidemia, porém, que se pode difundir e devorar vidas por todo o território nacional, é matéria de exclusivo interesse do município ou do Estado!

Para haver vislumbre de lógica deveria ser só do município que é a célula administrativa.

O nolli me tangere rio-grandense, esse perigoso quisto das instituições nacionais, as susceptibilidades dos Estados poderosos, têm sido e continuam a ser os grandes óbices à reabilitação sanitária do país perante nós mesmos e perante o mundo civilizado. E se a nós brasileiros cabe apenas clamar contra um estado de coisas que ameaça de naufrágio a nossa nacionalidade, ao estrangeiro o mesmo não acontece. Precisamos de renome sanitário como o indivíduo de ar para viver - a importação do que nos é imprescindível, a exportação do que produzimos, o colono, o capital, nos serão trancados, se cuidado máximo com a saúde do homem, no nosso país, se não patentear bem real e profícuo.

É lícito crer na insinceridade dos que repelem a unificação geral dos serviços de saúde pública, como atentatória das autonomias estadual e municipal, pois ela se reflete fragrantemente nas constituições e leis estaduais. Nenhum Estado se julgou ainda inibido de entrar no território de um Município, criar e executar nele serviços sanitários por leis e funcionários estaduais. Entretanto é nos mesmíssimos termos que a Constituição Federal define a autonomia dos Estados e dos Municípios. Se a União não pode, sem o consentimento do Estado, proceder nele a serviços sanitários, também o Estado não o pode fazer no Município sem o mesmo consentimento deste. Em geral os régulos estaduais são tanto mais ciosos de sua independência do poder central, quanto mais golpeadores das verdadeiras prerrogativas municipais.

Neste debate para unificação dos serviços de saúde pública, muitos já concedem que a debelação das epidemias, pela possibilidade da generalização destas, deva competir à União. Tão somente a debelação das epidemias.

Os que assim afirmam não são médicos ou desconhecem por completo a higiene. Porque, aceitando aquele princípio, é preciso aceitar todos os corolários que a técnica científica, hoje muito exata e muito rigorosa, deve impor. Discutamos apenas com as moléstias epidêmicas sobre as quais a União, em seus tratados internacionais, se compromete providenciar. Não é possível combater nenhuma daquelas moléstias com segurança, nem defender-se de nenhuma delas de modo eficaz, sem assumir, por completo, ingerência total nos serviços sanitários da localidade. Providências múltiplas e complexas se tornam imprescindíveis - com relação às condições higiênicas das habitações e aos hábitos sanitários dos moradores, com relação ao solo, às águas, à remoção das imundícies etc. Desçamos a 
minúcias. Como fazer o combate à febre amarela, que visa ao mosquito Stegomya calopus, em localidade contaminada, como defender uma povoação ameaçada, sem penetrar no interior das habitações em busca de qualquer caso febril em seu início e para o exame dos depósitos e coleções d'água, sem exigir dos poderes locais e dos proprietários, obras e melhoramentos nos escoadouros, nos encanamentos, nos depósitos das águas, nas instalações das latrinas e mictórios das habitações, lugares e logradouros públicos? Como fazer a profilaxia defensiva ou agressiva da peste, que visa ao rato, sem exigir dos proprietários, das grandes empresas, dos poderes locais, profunda remodelação no solo das edificações, nas paredes dos compartimentos destinados a conter gêneros alimentícios, na remoção das imundícies (lixo das casas e das ruas, restos alimentares, matérias fecais), nas condições dos mercados, no comércio de gêneros alimentícios, nos armazéns e depósitos de cereais e outros, nas habitações, nos paióis dos plantadores, nos armazéns das empresas de transporte etc. etc.? Julgo não precisar ir avante na demonstração.

E por que não é dado aos poderes locais - Estados e Municípios - se desempenharem satisfatoriamente das funções sanitárias em geral?

Por dois motivos essenciais. Em primeiro lugar porque toda e qualquer providência de higiene defensiva ou ofensiva demanda grandes despesas e grandes sacrifícios, grandes lutas. E todos sabemos quais as atuais condições financeiras dos Estados, em geral, e dos Municípios, sem exceção, no nosso país. Em segundo lugar, pelos mesmos motivos por que a administração pública, nas democracias atrasadas, de povos incultos, é tanto mais difícil de ser realizada quanto menor o seu âmbito de ação. Parece paradoxo mas é a realidade. A autonomia comunal, nos países do novo mundo, salvo talvez a América do Norte e o Canadá, é o pretexto para a pilhagem dos dinheiros públicos. No Brasil, a administração pública, é, na União, a desordem, vai ao descalabro nos Estados, chega nos Municípios à negação completa.

Fora das conveniências do mandonismo local, as leis estaduais, no município, são letra morta. Só as federais são cumpridas, só as federais são acatadas, só os serviços federais realizados, só a força federal temida. Não admira, portanto, que só os serviços sanitários federais possam ser realizados.

Não se argumente com S. Paulo, com Minas, com os Estados ricos e adiantados que dispõem hoje de organizações sanitárias.

S. Paulo, por exemplo, as possui desde Cesário Motta na Secretaria do Interior; Minas, desde a administração Bernardes. Conheço um e outro. No interior do primeiro, exerci a clínica durante quatro anos; na Zona da Mata do último, dirigi, durante um ano, os serviços de Profilaxia Rural. Como fatos característicos cito os seguintes. Em S. Paulo: - O Inspetor Sanitário do tracoma, em Ribeirão Preto, foi demitido por não ter querido aceitar para enfermeiro o carreiro boçal de um chefão político; de outro município, um curandeiro influente conseguiu a remoção acintosa do médico do governo. Em Minas: - Enquanto os serviços dependiam em grande parte dos poderes locais, os trabalhos se limitaram a propaganda e tratamento dos doentes, ficando inteiramente de lado o saneamento propriamente dito. Um detentor de executivo local, médico ilustre, meu amigo e apologista entusiasta dos intuitos da repartição, me disse um dia: - não me exija intimar e muito menos multar Fulano, adversário manso que não convém irritar, nem Sicrano, correligionário 
de valor que não posso perder. Arranje-se como puder, contanto que me não seja pedida qualquer ação coercitiva. Estivessem pois os serviços daqueles dois Estados nas mãos da União e a sua eficiência seria muitas vezes maior.

É que sobre os Estados, ainda os tidos como bem administrados, premem muito mais as injunções políticas do que sobre a União. Sobre os municípios muito mais ainda. Estas, tendo que transbordar do município e ultrapassar o Estado, vão diminuindo de importância e ao atingir a União se acham inteiramente desvalorizadas.

No Estado da Bahia só tem havido um embaraço à missão do Saneamento, embaraço, aliás, geral a todo o país - o da ignorância mais completa das vantagens e benefícios dos nossos trabalhos, da falta mais absoluta de qualquer instrução sanitária, embaraço que vou lentamente removendo com intensa propaganda e extensa difusão de noções de higiene. E tenho conseguido muito: - os postos, a princípio recebidos com indiferentismo e até com certa hostilidade, são hoje solicitados com empenho. Vários municípios já se têm prontificado a concorrer com auxílios e verbas especiais para obter os serviços. Alguns dos postos atuais já são, como mostrarei adiante, eficazmente secundados pelos respectivos poderes municipais.

E devo deixar aqui consignada a sincera gratidão que devo ao Governador do Estado, Ex. Sr. Dr. José Joaquim Seabra, pela acolhida fidalga que sempre me dispensou pessoalmente, pelo apoio e prestígio de que sempre tem cercado os serviços e os funcionários que dirijo. E cito dois fatos que talvez só neste Estado se hajam passado. Estando aqui há quase dois anos, e tendo em minhas mãos numerosas nomeações, não recebi de S. Exa., até hoje, um só pedido para colocação de protegido político; por outro lado, mantendo-me escrupulosamente alheio às competições políticas do Estado, preenchi alguns cargos com indivíduos que se me impunham por aptidões especiais mas eram adversários declarados do seu governo. Mantendo-se em atmosfera superior e serena, S. Exa. só se envolveu com os meus trabalhos para interessar-se pelo seu bom andamento ou para, a pedido meu, resolver-lhes e aplainar-lhes dificuldades.

Concluindo. O enfeixamento de todos os serviços de higiene e saúde pública nas mãos do governo federal se impõe como meio único de obter resultados reais e proveitosos. Que ao menos sofram os estaduais controle e fiscalização da União ou que se façam segundo bases e moldes determinados, de modo a serem chamados à ordem quando mal praticados. Já não exerce a União a fiscalização do exercício da medicina e da farmácia? Já não fiscaliza o fabrico dos soros e vacinas? Não vai decretar o código sanitário a ser observado em todo o país? Já alguns Estados, como Pernambuco e Pará, não entregaram todas as suas repartições de higiene e saúde pública ao Departamento? Em Minas não estão enfeixadas as providências federais e estaduais nas mãos de um só diretor? Já nos municípios onde há postos de Profilaxia Rural não vigoram só as leis federais executadas pelas autoridades federais? Quando isso se não faça, que ao menos nos Estados onde se proceda ao combate de qualquer epidemia, assuma a União os serviços. Foi com essa preliminar que Oswaldo Cruz se comprometeu a extinguir a febre amarela no Rio de Janeiro e foi por tê-la obtido que o seu êxito foi completo.

Para mostrar a balbúrdia que, apesar de todos os esforços do Departamento, reina em nosso país em matéria sanitária, bastam os fatos seguintes. 
Os serviços de saneamento e profilaxia rural são desempenhados pela União mediante acordo com o Estado. Para que se realize o acordo é mister "que o Estado preliminarmente aceite e promova a aceitação, pelos municípios, de todas as leis sanitárias do Departamento de Saúde Pública relativas ao assunto". Assim, instalada a Profilaxia Rural em um município, passam a vigorar nele as leis sanitárias da União, a serem executadas, é óbvio, pelas autoridades federais; desde esse momento, cessa a interferência dos poderes locais no assunto. Mas estes serviços têm começado, em quase todos os Estados, pelas suas capitais, todas elas tão carecedoras como qualquer localidade sertaneja. Assim como um prefeito da capital federal declarou que os sertões do Brasil começavam nos bairros de Vila Isabel e Engenho Novo, pode-se também afirmar que as zonas rurais dos Estados, sob o ponto de vista das condições e necessidades higiênicas, começam em suas capitais. Pode mesmo ser asseverado que os postos nelas instalados são geralmente os mais trabalhosos por se defrontarem com problemas muito mais complexos. Pois bem, nas capitais dos Estados que acordaram na instalação de tais serviços, em vez de ter desaparecido a interferência da ação estadual e municipal, como nos municípios do interior, persistiram as duas higienes locais, acrescidas desde então da federal. O resultado dessa anomalia, por melhor que seja a boa vontade e desejo de harmonia entre as três repartições é, senão a falência dos serviços, pelo menos a balbúrdia, a confusão, a perda de energias, o desperdício de dinheiros.

Isto quanto aos serviços de saneamento e profilaxia rural. Quanto aos de epidemias, que o governo de certo tempo para cá (governo Delfim Moreira) parece ter considerado de alçada e obrigação, porque os vem custeando inteiramente pelo tesouro federal, têm sido sujeitos a alternativas e contramarchas. O Rio Grande do Sul recusou-lhe os serviços contra a peste e a peste deixou de ser combatida no Rio Grande do Sul para sê-lo apenas em Alagoas, no Maranhão e outros Estados. Na Bahia, o governo só chamou a si a profilaxia da febre amarela, deixando com o Estado a da peste.

Ora, ou o governo federal considera ou não considera obrigação sua combater estas duas epidemias; reconhece ou não reconhece ter competência legal para realizar tais trabalhos; tem ou não tem confiança nos Estados para de tais encargos se desobrigarem. Se considera obrigação sua, se acredita ter competência legal, se não confia na ação dos Estados, deve promover a extinção de ambas as epidemias em todo o território nacional e nunca concordar em fazê-lo apenas neste ou naquele ponto. Para anular todos os esforços, perder todos os gastos, basta que, no país, um Estado, um município, um lugarejo deixe de ser expurgado do mal. Extinto ele por toda a parte e cessados os serviços, voltará de novo a se espraiar, a se irradiar, do pequeno foco em que ficou inatacado.

Esses mesmos trabalhos, regionais e salteados, quando já adiantados, quando os focos mais intensos se iam extinguindo, foram suspensos, de chofre, por ordem direta do então Presidente da República, sob a acusação de 'comissões que se eternizavam' e consumiam grandes verbas, como se nestes casos fosse possível marcar prazos e prefixar despesas. E os Estados que, confiantes na ação do governo federal, se haviam por completo desaparelhado de pessoal habilitado e material apropriado, o que se não obtém de improviso, se viram, de momento para outro, em situação de angustioso abandono. Não para aqui o desastroso efeito de tal resolução. Veio ele a ferir fundo o prestígio dos serviços sanitários federais. Até então, sempre que se devia proceder a trabalhos de profilaxia em qualquer município, 
encontravam os funcionários todas as facilidades para sua instalação e manutenção, porque se vinham tendo como certos os pagamentos a quaisquer débitos contraídos; a suspensão brusca dos serviços, com cinco meses de atraso nos pagamentos e sem que até esta data, mais outros cinco meses decorridos, haja o menor indício de satisfação a tais compromissos, fez cair em completo descrédito o conceito em que era tido o governo federal e criar grandes dificuldades para futuros empreendimentos.

Pela lei orgânica do Departamento, cabe ao serviço de Profilaxia Rural, na localidade onde houver Posto, o combate não só às endemias, como a qualquer mal epidêmico que porventura ocorra. Como, porém, fazê-lo sem aparelhos, sem drogas, sem adequado pessoal?

Os serventes dos postos, capazes de ser mata-mosquitos e os empregados capazes de se arvorar em desinfetadores, ou não existem ou são sempre em número diminuto. Dispondo ocasionalmente de uns e outros, foi-me possível fazer a profilaxia da peste em Juazeiro e a da febre amarela nesta Capital e em S. Felix, custeando porém os trabalhos pela verba da Profilaxia Rural. Mas se este serviço se faz em virtude de contrato entre a União e o Estado, entrando cada parte contratante com metade das despesas; se a União não consente que se gaste com profilaxia rural um real da verba de epidemias, como consente, como exige mesmo, que com a verba do contrato se despenda com epidemias? Parece-me que neste caso caberia ao Estado o direito de protesto. Tudo isto precisa ficar bem claro e bem regulado em benefício do público e para tirar os chefes nos Estados de embaraços e perplexidades.

Para concluir. Penso que para o Departamento assumir o compromisso de libertar o país da febre amarela e da peste, sem falar em outras moléstias epidêmicas, é preciso:

$1^{\circ}$ - Fazer a profilaxia em todo o território nacional em que o mal se apresente.

$2^{\circ}$ - Chamar a si, nesses lugares, pelo menos, e numa área que se estenderá ao critério das exigências técnicas, todos os serviços de higiene e saúde pública.

$3^{\circ}$ - Custeá-los com uma só verba facilmente deslocável de um para outro Estado, de uma para outra região, segundo reclamarem os acontecimentos; verba que deve ter a extensão das necessidades.

$4^{\circ}$ - Dar-lhes, com unidade de direção, unidade de técnica e de orientação.

$5^{\circ}$ - Interessar na campanha os poderes locais, os clínicos, a imprensa, a opinião pública.

$6^{\circ}$ - Fazer permanecerem e continuarem os serviços em certos pontos estratégicos, enquanto a extinção do mal não for completa e definitiva em todo o país. Pelo que diz respeito à febre amarela, por exemplo, a capital da Bahia, por motivos que já tenho expendido em anteriores relatórios, não pode dispensar uma defesa, permanente, enquanto o mal persistir em qualquer ponto do país.

Com este programa e dentro destas linhas gerais, penso que V. Exa. poderia assumir, perante o atual governo, o compromisso de, dentro do quatriênio, expurgar da peste e da febre amarela o território nacional. Sem meios amplos de ação melhor será deixar inteiramente de lado o problema, para não só evitar a perda certa de energias e dinheiros, como salvaguardar o prestígio do Departamento e da própria ciência. 


\section{Combate à peste}

Na Bahia está este serviço a cargo do governo do Estado. Como entretanto ocorressem casos em Juazeiro onde há posto de Profilaxia Rural, enviei para ali imediatamente todos os recursos para combate intenso e rápido. Felizmente conseguimos apanhar o mal em seu foco inicial que foi eficazmente destruído, não tendo, até esta data, aparecido mais caso algum. Os seis casos surgiram ao mesmo tempo e no mesmo lugar. 